\title{
DO NARRAR O VIRTUAL E O REAL: EXPERIÊNCIA DE UMA TRADUÇÃO
}

\author{
Mauren Pavão Przybylski ${ }^{1}$
}

\section{Situando o campo}

Começo esta reflexão a partir do pensamento de Michael Pollak vê a memoria não só como seletiva, mas como um processo de negociação para conciliar memoria coletiva e memorias individuais. Ele traz Halbwachs para justificar que "Para que nossa memoria se beneficie da dos outros, não basta que eles nos tragam seus testemunhos: é preciso também que ela tenha deixado de concordar com suas memórias e que haja suficientes pontos de contato entre ela e as outras para que a lembrança que os outros nos trazem possa ser reconstruída sobre uma base comum".(1989: 3-4)

Justamente por ser uma construção humana deve-se também considerar as imagens e os discursos que as pessoas elaboram do espaço em que ocupam, pois é lá que acontecem os conflitos, o convívio social, as trocas de informações, as sensibilidades e as práticas que conferem sentidos e significados. A cidade deve ser vista e analisada não somente pelas suas construções arquiteturais e suas possíveis ocupações no espaço, mas antes pela dimensão da existência, pois ela é construída por homens e suas relações.

Essa fluidez do tempo e efemeridade dos processos de sistemas de representações simbólicos (imagens e valores) que caracterizam a vida na cidade e as quais as antropólogas Ana Luiza C. da Rocha e Cornelia Eckert (Eckert e Rocha, 2005) destacam são bastantes presentes nas estórias contadas na Restinga e que registramos em audiovisual e ambiente virtual. O sentido de lugar que cada morador tem é diverso, mas o objetivo é o mesmo: a constituição de um acervo de memória do bairro.

É fato, a partir disso, que nem sempre o que buscamos no bairro é o que vamos escutar. Existe uma negociação interna que perpassa não só aquilo que o narrador conta, mas aquilo que ele pensa que queremos ouvir. Assim, ele seleciona fatos que julga serem importantes e que, na maioria das vezes, não são os que queremos ouvir, mas o que ele tem para contar. São seleções que partem do que ele deduz ter de melhor em sua individualidade e que pode servir para valorizar o coletivo. Entendo bastante esta afirmativa de Pollack no contato com um narrador da Restinga ${ }^{2}$. José Carlos dos Santos,

\footnotetext{
${ }^{1}$ Universidade Federal do Rio Grande do Sul, Brasil.

2 A Restinga, mais conhecida por seus moradores como "Tinga", é o maior bairro de Porto Alegre, localizado ao sul da cidade. Foi criado pela Lei 6571 de 8 de janeiro de 1990. No entanto, sua origem
}

Iluminuras, Porto Alegre, v.12, n. 29, p. 199-218, jul./dez. 2011 
o Beleza, ${ }^{3}$ aposentado, ex-conselheiro tutelar, militante por uma Restinga com memória e valor reconhecido, nos afirma, a cada história contada, uma reconstrução da lembrança sobre uma base comum. A base comum, nesse caso, é a Restinga idealizada, uma Restinga que existe na memoria de cada morador. Ao trazer fatos que ele afirma reais, ele representa a realidade do bairro de forma a misturar verdade e fantasia.

Por outro lado, Marco Almeida, o Maragato é mais pragmático e também se mostra mais traumatizado em função de situações de preconceito que ele julga advirem de sua condição financeira e sua raça, visto que é negro. Contudo, é alguém que mesmo exalando este rancor, numa atitude completamente contraditória, sabe se impor. Muitas vezes, ao chegarmos para as reuniões de pesquisa, ele já tinha sua pauta que era sempre de cunho prático, buscando pontuar o que tinha realmente sido realizado e apontando o que ele pensava poder ser melhorado. Maragato é versátil, de uma versatilidade que advém de suas circunstancias e faz dele alguém capaz de desempenhar diversos papéis (e ao mesmo tempo) na sociedade. De manhã educador popular, à tarde catador de lixo e/ou vendedor de algodão doce e no tempo que sobra autor de diversos blogs, poesias e pequenas historinhas em quadrinhos. Seu conhecimento de internet é autodidata e seu objetivo é que ela seja uma ferramenta de educação; ele quer mostrar aos jovens da Restinga o outro lado da rede que não somente o das salas de bate-papo e/ou redes de relacionamento. Através de um programa que ele descobriu, Maragato cria histórias em quadrinhos, leva para seus alunos quando desempenha o papel de professor, e os ensina a criarem suas próprias. Para ele, esta é uma forma de incentivar as crianças e adolescentes a adquirirem o habito da leitura. Maragato luta por uma verdadeira inclusão digital, capaz de qualificar as crianças na realização de seus sonhos e que as possibilite um futuro melhor. Sua fala é política, seus registros audiovisuais mínimos, ele prefere o virtual ao real, mas entende a necessidade do real para a realização de seu engajamento político. Afinal de contas, os dominantes não podem jamais controlar perfeitamente até onde levarão as reivindicações múltiplas e dificilmente previsíveis.

remonta há algumas décadas antes e é marcada por uma série de remoções de moradores indesejados das áreas centrais da cidade, que tinham que ser "higienizadas" para dar lugar a espaços planejados, sinais do progresso urbano. A Lei de 30 de dezembro de 1965, que criou o Departamento Municipal de Habitação (DEMHAB), transferiu tais habitantes para um local $22 \mathrm{~km}$ longe do centro de Porto Alegre, a Restinga. E é nesse bairro, permeado por intensas dificuldades socioeconômicas, políticas e culturais, que vivem Jandira, Maragato, Beleza, Alex e Ventura, nossos parceiros e narradores.

${ }^{3}$ Nesta discussão tomaremos como sujeitos de pesquisa Marco Maragato e José Carlos dos Santos, Beleza, por serem bastante significativos naquilo que queremos relatar. 
$\mathrm{Na}$ tirinha abaixo o que percebemos são imagens ${ }^{4}$ que querem retratar a realidade de um morador do bairro considerado subúrbio de Porto Alegre e que faz uma crítica não velada acerca do modo como a sociedade vê os indivíduos moradores da Restinga.
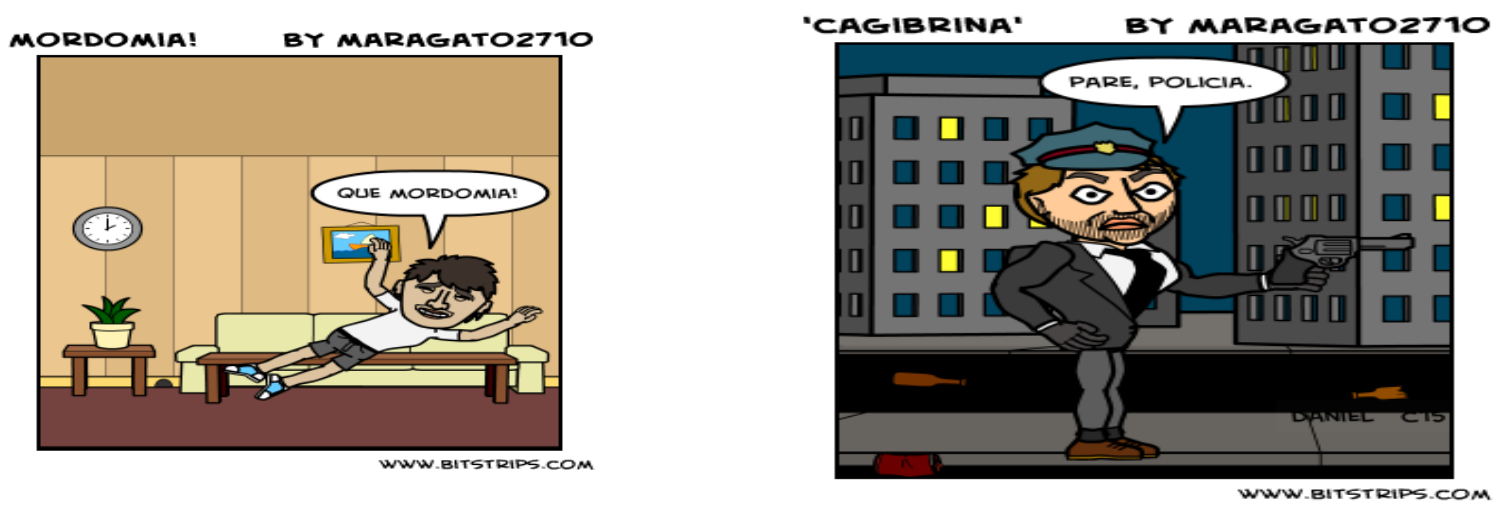

$\mathrm{Na}$ seguinte, vemos a criação de uma aluna que retrata a imagem de uma provável secretária. Talvez, seja o imaginário que ela tem formado em relação ao seu futuro; o que ela almeja ser.

'UM DIA DE TRABALHO'

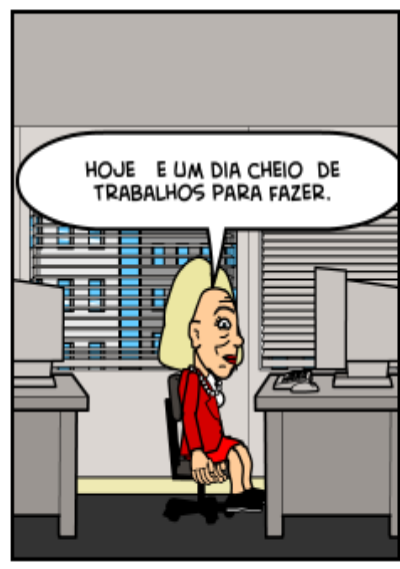

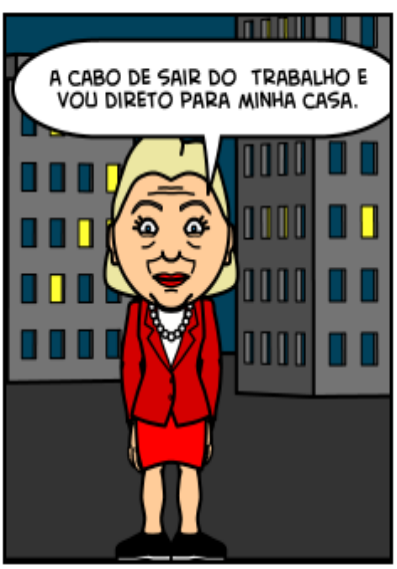

BY MARAGATO2710

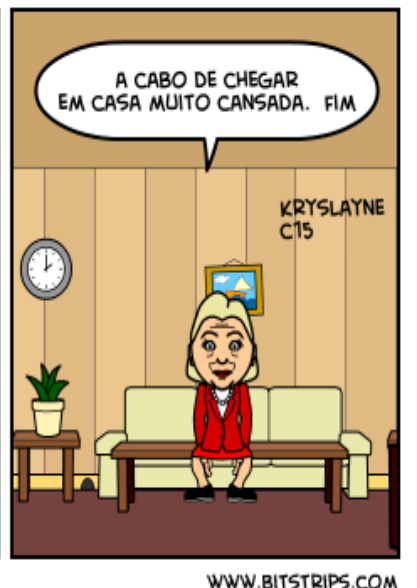

\footnotetext{
${ }^{4}$ Essa e as demais imagens (tirinhas e blog de Maragato, bem como foto e imagem da camiseta de Beleza) estão em nosso site e o uso nos foi autorizado pelos narradores.
} 
Maragato conta sua vida através de ações, através do trabalho. É inegável que por trás de todos seus "ensinamentos" estão a realidade de alguém que não teve formação acadêmica e que quer uma realidade diferente aos seus jovens e crianças. Ele não é o que chamaríamos de um contador, como, por exemplo o é Beleza, mas ele trabalha em cima da coisa contada, pensando sob uma perspectiva ricoeuriana ele é a parte pratica de tantas teorias e constrói narrativas e estórias que podem ser mitificadas por quem as lê.

O blog "Maragatopg" é o espaço que ele encontra para publicar uma de suas produções, o livro baseado em histórias em quadrinhos intitulado "JK no país das calças beges".

Ao perguntarmos o significado de JK ele não atribui a nenhum cunho politico, ao contrário, diz que foi o que veio em mente no momento de nomear sua história.

O que nós fazemos, enquanto pesquisadores é linkar seus sites ao nosso como forma de valorizar seu trabalho e seus objetos de memória de uma Restinga que é retratada a partir das novas tecnologias... e que essas novas tecnologias são exploradas por seus moradores.

'ANA NO PAIS DAS CALAS BEGES

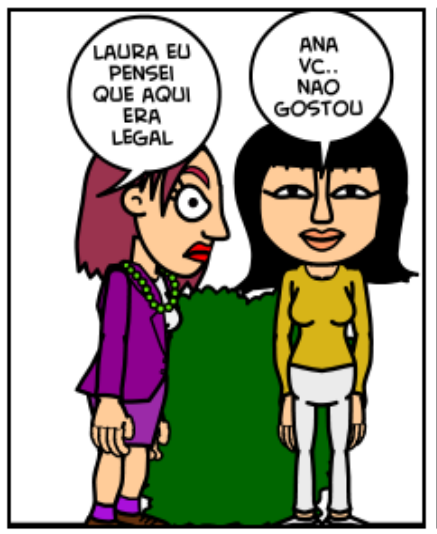

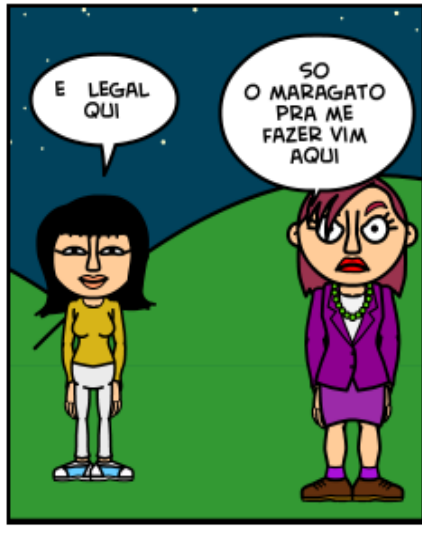

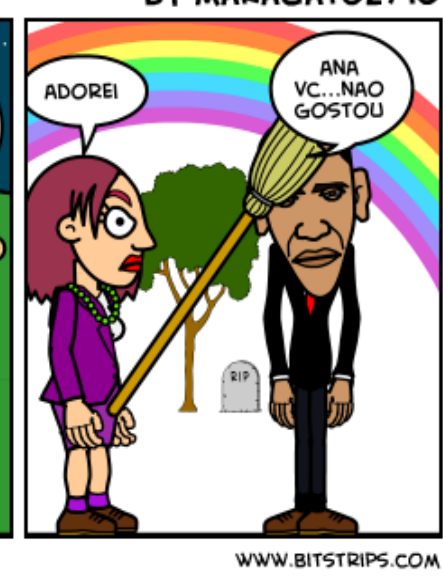


Interessante ver, nessa segunda tirinha, que Maragato usa seus conhecimentos de informática para fazer uma crítica da relação que ele, narrador e parceiro, estabelece com a coordenadora e os membros do projeto. Sabemos que por mais que entendamos nossa relação com os narradores como parceria, haverá certa tensão o tempo todo, na medida em que eles confiam em nossas intenções, desconfiando. É preciso que haja resultados práticos para que essa confiança ganhe força.

\section{O contar tradicional e o contar virtual: aproximações e distanciamentos.}

Quando se pensa em narrativa é natural que se pense também na questão do mito. O que determina que algo contado é de origem mítica?

Rogerio Carvalho, em seu projeto de pós-doutorado, traz Durand para entender que o mito está sempre presente na capacidade de o ser humano de simbolizar, seja através de imagens propriamente simbólicas ou por motivos arquetípicos. Ou seja, para ele, o imaginário é o centro da habilidade que o homem possui de transcender e que, pouco variando, se realiza sob a forma de imagens simbólicas e de narrativas arquetípicas. Na Restinga, o que temos, são estes tipos de narrador, alguns mais poéticos, outros nem tanto, mas todos capazes reproduzir imagens simbólicas como forma de resgate primeiro de uma memoria pessoal, depois da do bairro.

Paul Ricoeur atribui ao ato de presentificar a distinção entre o fato de "contar" e a coisa "contada". Para o autor:

\footnotetext{
O que é contado e que não é narrativa, não é em si mesmo dado em carne e osso na narrativa, mas simplesmente "devolvido restituído" (Wiedergabe); por outro o que é contado é fundamentalmente a "temporalidade da vida"; ora "a vida [ela própria] não se conta, vive-se" (p.254). As duas interpretações são assumidas pela seguinte declaração: "Qualquer contar é um contar algo que não é narrativa, mas processo de vida" (p.261). Qualquer narrativa, desde a Ilíada, conta a própria fluência (Fliessen): "A epopeia é tanto mais pura quanto mais rica de temporalidade for a vida" ( "Je mehr Zeitlichkeit des Lebens, desto reinere Epik, 1995: 250).
}

$\mathrm{Na}$ Restinga percebemos fortemente essa ideia ricoeuriana, na medida em que o que cada morador quer é valorizar os tantos processos de vida presentes na comunidade. A fala de cada um, suas ações enquanto poetas, educadores populares, nômades cibernéticos objetiva ser essa descrição de uma temporalidade da vida. Suas narrações contam a fluência de uma comunidade, comunidade essa onde faz-se extremamente importante destacar que foi removida de seu locus primeiro de morada por uma questão de higienização urbana. 
Cabe ressaltar que o objetivo deste trabalho é analisar a passagem do oral para o escrito e todas as perdas e ganhos do processo, mas, para isso, precisamos contextualizar nosso estudo. A Restinga é nosso locus de trabalho e os sujeitos acima citados nossos "sujeitos de pesquisa".

A experiência de composição de um site pode ser muito mais do que uma simples técnica. Para isso, basta que a página a ser criada pretenda dar conta de narrativas, narrativas que são certamente de cunho ficcional, mas que vem de personagens/narradores reais. A composição do site "A Vida Reinventada: pressupostos teóricos para análise e criação de acervo de narrativas orais" foi, e continua sendo, para mim, um desafio.

Nesse sentido, entendo a construção de um site na esteira daquilo que entendem Eckert e Rocha (2000):

\begin{abstract}
A concepção da arquitetura do site tem se constituído na expectativa da leitura/interpretação do objeto cidade pelo usuário do site no sentido de confrontá-lo com dois tipos de divisibilidade das imagens dos fenômenos urbanos, no espaço e no tempo: o corte e a ruptura. Neste ponto, corte e ruptura têm sido tomados aqui como elementos indutores de narrativas etnográficas do e no meio urbano de Porto Alegre uma vez que, através de ambas as ações, os usuários exploram o conhecimento local do fenômeno do "desencaixe" do tempo e do espaço tão característico da Modernidade. Trata-se de evitar ordens discursivas acerca das transformações dos cenários da vida coletiva em Porto Alegre e a tendência de transformar coleções etnográficas em depósitos ordenados de uma cultura material, dispostas numa lógica evolutiva.
\end{abstract}

Nosso objeto, por sua vez, é o objeto-bairro. É a Restinga vista de dentro e de fora, por nós, mas principalmente por seus moradores que executam por vezes cortes no tempo e no espaço como forma de restaurar aquilo que lhes é mais caro na constituição e uma identidade do bairro. A página internet em si propicia uma desordem discursiva, na medida em que cada um lerá e interagirá da maneira que melhor lhe convier. O acervo de narrativas, por sua vez, transformará todo aquele material recolhido na Restinga em objetos de cultura material que estarão ao acesso de quem sem interessar, ao invés de virarem meras coleções etnográficas guardadas em uma sala.

O que se quer é a recuperação tanto de um bairro, a Restinga, no que tange as suas histórias de vida e a possibilidade de que as pessoas criem um novo olhar, que não aquele de lugar violento e de moradores marginais, sobre a Restinga, quanto uma revaloração de tantas histórias de tantos sujeitos que se viram perdidos pela supremacia de um mundo tecnológico. Nossa intenção é unir tecnologia e narrativa como forma de 
auxiliar no resgate de estórias que fazem parte da própria constituição da sociedade moderna. $^{5}$

Deparei-me com uma quantidade imensa de materiais a serem transferidos para o ambiente virtual, materiais que davam conta de aproximadamente quatro anos de pesquisa. Mas a dificuldade não estava somente na quantidade, mas no modo de fazer, pensando na concepção de De Certeau. Eu estava lidando com trabalhos de indivíduos com os quais tenho contato, que tem voz, ideias próprias e uma expectativa em cima de mim. Como eu lidaria com a memória deles? Sim, entre outras coisas nosso projeto se pretende enquanto um arquivo de memória, onde as pessoas deixam seus registros em áudio, vídeo, daquilo que para elas é mais importante, do que elas valorizam em si, em suas comunidades e querem que seja destacado. A maior parte do que temos é advindo da Restinga e isso não é à toa, visto que o bairro é o nosso locus de pesquisa de campo. ${ }^{6}$

Ao ter em mãos a tarefa de passar do oral para o escrito as memorias das pessoas e sendo esse escrito o ambiente virtual me deparei com muitas questões: como fazer? De que modo coloca-los preservando suas verdades? Deveria eu corrigir os erros, por exemplo, de ortografia em alguma poesia ou texto dos meus narradores ou seria intervenção demais?

Meus questionamentos foram partilhados com o meu grupo de pesquisa, na medida em que eu fui um instrumento para que aquele material fosse ao ar, mas não idealizei cada titulo de menu e sub-menu sozinha. Quando falo em partilha é preciso que eu deixe bem claro que, mesmo não sendo talvez, para muitos, a forma ideal de trabalhar, nosso projeto prima por uma construção coletiva de saberes e conhecimentos e, por isso, fui também atrás de meus narradores para que eles dessem suas opiniões e contribuições. Dessas opiniões foram, certamente, feitas escolhas. E esse é o momento que julgo mais delicado porque, se eu estou escolhendo materiais e deixando outros de fora, eu estou, de uma certa forma, intervindo na verdade do narrador. Onde fica, nesse sentido, meu objetivo maior de manter sua verdade?

Alguns cuidados foram tomados em nosso processo de passagem das narrativas e demais materiais para o ambiente virtual. O primeiro foi o de colocá-los, se não lado a

\footnotetext{
${ }^{5}$ Não nego a importância de um relato teórico acerca da poeticidade dessas narrativas, entretanto, este texto é apenas um primeiro recorte de minha tese de doutorado que está em fase inicial e pretende, em um segundo momento, contemplar a questão poética.

${ }^{6}$ Utilizo o plural e o singular, o nós e o eu, de forma proposital, na medida em que minha tese está engajada em um projeto de pesquisa intitulado "A Vida Reinventada: pressupostos teóricos para análise e criação de acervo de narrativas orais" e que, mesmo tendo sido publicado por mim, foi pensado por todo o grupo de pesquisa. Minhas reflexões são, portanto, fruto de discussões semanais proporcionadas por este grupo.
} 
lado em termos físicos por uma impossibilidade técnica, logo abaixo de nossas descrições no ambiente virtual. Depois, os colocamos como Colaboradores, porque é isso que eles são. $\mathrm{Na}$ verdade, se fossemos realmente defini-los em um menu colocaríamos Sujeitos-parceiros de pesquisa, mas existem questões de técnica e estética que precisam ser obedecidas. E finalmente colocamos Outros Colaboradores que, se pensássemos sob uma perspectiva em primeiro lugar acadêmica e canônica deveriam vir antes, na medida em que são professores de outras instituições, pesquisadores. Nosso objetivo não é uma valorização de nosso trabalho intelectual, mas o de criar um espaço de memória tanto para os moradores da Restinga quanto para todas as pessoas que quiserem registrar fatos que julgam importantes acerca de sua existência e valorizaremse enquanto indivíduos que possuem um lugar no espaço.

Nosso desenho virtual continuou no momento em que criamos mais um menu: o Imagens. Dentro dele: Etnografias. Nesse, nosso objetivo é publicar os registros produzidos principalmente na casa do morador José Carlos dos Santos, o Beleza, documentando os momentos de produção de narrativas orais. Uma das fotos mais interessantes presente neste sub-menu é a da defesa de um atualmente membro externo do projeto, mas que produziu a primeira dissertação do nosso grupo de pesquisa, Felipe Ewald, em que três moradores da Restinga: Marco Almeida “ O Maragato”, José Carlos dos Santos “O Beleza” e José Ventura aparecem sentados naquelas cadeiras que outrora foram ocupadas pelos membros da banca de defesa, contando suas experiências.

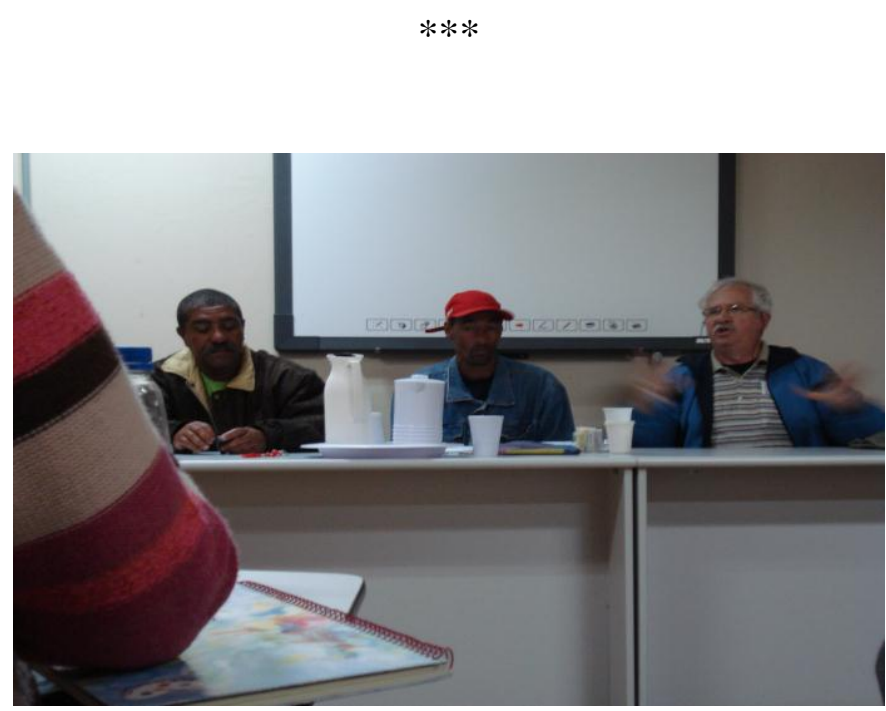


A imagem foi recebida pelo publico, composto então por professores renomados de universidades como UFMG e UEL, de forma "chocante", não no sentido estereotipado da palavra, mas na medida em que não esperavam que um catador de lixo, vendedor de algodão-doce como Marco Maragato, o do meio, pudesse proferir uma fala na academia e começasse citando Drummond e Quintana.

Esse momento, que julgamos histórico para a nossa pesquisa, está registrado em nossas Etnografias que se pretendem enquanto um diário de campo virtual, em que as imagens dizem tudo o que as palavras muitas vezes não são capazes de alcançar.

Depois de darmos conta das etnografias partimos pelo que optamos denominar Memorabilia. Nele temos os objetos e registros das criações e produções dos narradores da Restinga. Aqui é possível encontrar-se, entre outras coisas, as poesias produzidas por dois moradores: Alex Pacheco e Jandira Brito. Os descobrimos poetas e os fizemos (re) descobrirem-se poetas a partir da valorização em seu trabalho. Nossa valorização não é algo que fique no campo da oralidade, mesmo que nosso objeto de pesquisa sejam as narrativas, e com muitos esforços conseguimos publicar um livro com as poesias de nossos ilustres parceiros. A escolha das poesias, bem como das imagens do sub-menu anterior, foi feita de acordo com o que sentíamos ser mais caro aos narradores. Nossa escolha precisou, ao longo de todo o site, ser baseada na sensibilidade e na experiência que parte do contato no campo. Não encontramos outra opção que pudesse ir ao encontro do objetivo traçado. No que tange a esta Memorabilia ainda é mister destacar o trabalho desenvolvido pela geografa Nola Gamalho. Ela, juntamente com o morador Beleza, fez a trajetória do bairro, foi o caminhar pelo bairro (se parafraseamos De Certeau) de Nola e Beleza que permitiram a confecção de um mapa atualizado da Restinga. Diferentemente daquele fornecido pelo DEMAHB, Nola mapeou cada unidade que compõe a Restinga. 

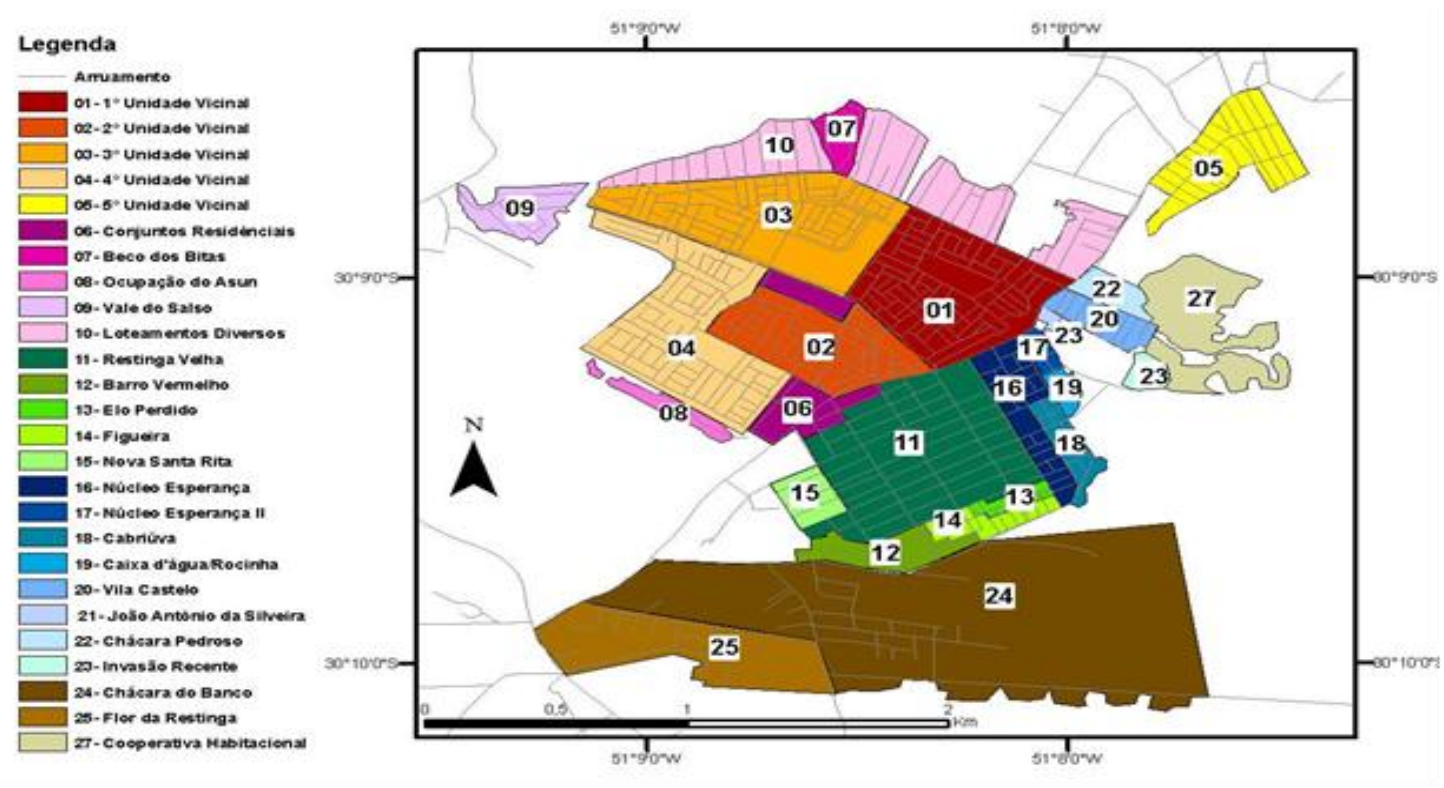

Mapa produzido pela geógrafa Nola Gamalho em sua dissertação de mestrado.

Ao ser mostrado aos moradores, numa exposição realizada pelo Grupo de Pesquisa ${ }^{7}$, foi interessante a percepção de cada morador acerca de seu locus de morada. A impressão que tivemos é de que muitos deles não sabiam da diversidade cultural e geográfica de seu bairro. Questões políticas internas também vieram à tona na medida em que eles apontavam os locais de que não gostavam, onde não circulavam, os que julgavam mais ou menos perigosos. Foi um exercício de reencontro com sua identidade.

Ainda dentro das Imagens temos as Incursões. Neste sub-menu damos mais ênfase aos registros de experiência do grupo de pesquisa e do Projeto de Extensão quem conta um conto - contadores de histórias em diferentes espaços do bairro. Neste momento nossa voz pode falar com mais liberdade, na medida em que era nossa subjetividade que seria relatada de forma explicita. Todavia, a partir do momento em que lidamos com imagens produzidas por nós, mas que não são nossas, certos cuidados se fazem necessários. Nas situações de contação de histórias, por exemplo, muitas crianças aparecem e foi preciso distanciar seus rostos e preservar suas identidades por serem menores e não termos nem direito, nem autorização, de expô-las em ambiente

\footnotetext{
${ }^{7}$ Daremos ênfase à exposição na sequencia do relato.
} 
virtual. É fato que mesmo na internet existem normas que devem ser cumpridas, mesmo que nem sempre isso aconteça.

Em Museu de Imagens temos documentos escaneados, fornecidos por nossos parceiros/narradores, contendo registros de experiências, entre eles: jornais, cadernos, fotos pessoais, fotos de outros acervos, etc. Neste o cuidado com as imagens do qual falamos acima se faz também bastante presente.

E por fim Via Crucis vai dar conta da exposição de que citei acima. O nome da exposição foi sugerido por Marco Maragato em função da dor e sofrimento passado por esses moradores desde que aconteceu a remoção de seu antigo locus para onde estão atualmente. Cada estação conta um pouco da história da Restinga. Disponibilizamos, no site, as 10 estações para que quem se interessar (pensamos num interesse que partisse, sobretudo, dos educadores) pudesse ter acesso e trabalhar com isso em seu dia-a-dia. Da exposição, surgiu a ideia de realizarmos uma Oficina para os professores da rede pública do bairro. A aceitação primeira era grande, mas toda a vontade de conhecer o projeto terminava ao nos verem chegando junto com os moradores. O que a comunidade escolar em geral queria era o contato com a Universidade, com alguém que os era “intelectualmente superior” em função de possuir um diploma. Mas que autoridade seus pares teriam para ensina-los algo? Muitos dos professores também não se interessaram pelo projeto pelo fato de ser um resgate da memória do bairro e eles não serem moradores. A eles não interessaria atravessar a cidade, no sábado, para ouvir moradores falarem. Em respeito aos poucos interessados, registramos no site.

O menu Textos e seus submenus dá conta do que nós, pesquisadores, vimos pensando. São relatos de nossas experiências passados para o papel através de artigos, publicações em livro, monografias, dissertações e teses, sendo que esta última dá conta de trabalhos que ainda estão em desenvolvimento.

No menu vídeos temos como objetivo disponibilizar alguns dos vídeos produzidos pelo grupo de pesquisa. Já temos pronto o Narradores da Restinga I e estamos em fase de produção do II e de um terceiro que dá conta da poética indígena. A experiência do vídeo ${ }^{8}$ nos é muito cara e ao mesmo tempo bastante nova. Questões como duração, em uma perspectiva bachelardiana, não foram por nós ainda contempladas. Nosso campo de estudo recai muito mais nas questões de memoria e

\footnotetext{
${ }^{8}$ Muito embora nosso objetivo não seja aqui discutir nossos vídeos, os traremos como exemplo ilustrativo de nossa pesquisa.
} 
identidade e como editar tudo isso vendo-nos como tradutores de mensagens políticas, sociais e de libertação de uma realidade que não agrada mais.

Já que falamos em imagens e citamos Gaston Bachelard é importante trazermos algumas questões acerca de seu pensamento.

Maria Paula M. S. Bueno Perrone em seu artigo intitulado "A Imaginação criadora: Jung e Bachelard" vai dizer que para Bachelard a imagem na perspectiva da psicanálise não tem essencialidade, precisa buscar seu significado fora dela, é simulacro sem vida autônoma que só se traduz através do conceito. "Além disso, está presa a uma temporalidade e a uma causalidade." E trazendo as palavras do próprio autor, acrescenta que: $\mathrm{O}$ homem por ele concebido é o homem demiurgo, instaurador de novas realidades, cuja fonte é a imaginação criadora, a essência do espírito humano, que de modo dinâmico o torna capaz de produzir tanto ciência quanto arte, ou seja, o pensamento e o sonho. Em Bachelard, a imaginação criadora une os dois mundos. Nessas diferentes faces da capacidade de criar a experiência psicológica está presente sob a direção do imaginário. Concebe a imaginação como fonte, como o que impulsiona o pensamento e o faz dinâmico, criando o novo como um grande susto, numa instantaneidade.

Acreditamos verdadeiramente que a imaginação é fator bastante presente no relato de cada um de nossos narradores, na medida em que fazem uma representação de suas realidades, de seus passados, de suas vidas. Esses relatos terminam no momento em que são proferidos, caracterizando a instantaneidade que lhes é peculiar. Diferenciar o que está na esfera do pensamento, do sonho ou da imaginação é tarefa bastante difícil. Os vídeos, por mais que sejam registros, não conseguem manter este instante que é o único. Isso porque, tomando como base a teoria de Émile Benveniste, da qual Ricoeur faz alusão, a enunciação é um momento único e que termina no momento em que se realiza. A realização do enunciado dá conta de seu inicio e também do seu fim. O que fica nos vídeos são gestos, voz, corpo, mas o verdadeiro enunciado se perde. E é praticamente impossível, mesmo no momento da edição, congelar esse instante poético.

No encontro realizado no dia 11 de novembro de 2007, logo no primeiro minuto de registro, Beleza destaca as escolas gradeadas, os alunos que queimavam a cabeça dos professores. Por tudo isso, ele foi chamado pelo promotor para tentar resolver a situação, visto que fora durante muitos anos conselheiro tutelar. Todavia, a grande questão é que várias pessoas da própria escola tinham preconceito e perguntavam o que ele sabia para estar lá dizendo o que dizia. Nesse momento aparece uma crítica que é forte e constante na fala de Beleza: a questão do diploma universitário. Outra crítica que 
ele faz é ao pensamento reflexivo. As escolas, ao punirem os alunos, o faziam anunciando: "Tá na hora do pensamento". - pensar era castigo. Os alunos não são incentivados à reflexão, mas sim a um ensino robotizado e teatral, alguns fingem que ensinam, outros que aprendem, e tudo fica bem. Se a enunciação termina, simplesmente pelo fato de que deveria terminar ou por ter sido bruscamente interrompido, a crítica permanece. É o que, Felipe Ewald, em sua dissertação de mestrado, vai chamar de narrativa movente. Vejamos o trecho de uma conversa entre o grupo de pesquisa e o Beleza, na casa dele, em 18 de setembro de 2009:

DANI: Falando em coisas difíceis, tu consegue contar de novo a história do navio negreiro?

BELEZA: acho que consigo... o Maragato me ajuda...

DANI: consegue? Como tu contou aquela lá / na que tu descreveu lá como é que era, como é que começou, da noite para o dia, o que acontecia...

BELEZA: a-hã...[silêncio profundo de dois segundos] em resumo, só para terminar a história, esse negócio da FASC aí era assim, ó. Depois ele/acabei indo para lá, o primeiro ato que eu tive lá e aí fiz questão de chamar todo mundo, né: tudo que era funcionário, vileiro, o cara que era atendido, a vóvo que eu cansei de saber que não tinham nem o que comer, né. Iam tirar as cinco horas da manhã, pra ganhar uma fichinha, pra ser/da possibilidade... não, que é isso. Não,vocês vão lá que a partir de agora...(Registro Audiovisual, 18 de setembro de 2006, 31')

Nesse registro percebemos que Beleza tem uma postura de enunciador com poder, ou seja, ele afirma que pode recontar a história do navio negreiro ${ }^{9}$, mas na verdade fala do atendimento na $\mathrm{Fasc}^{10}$. O fato de ele dizer que Maragato o ajuda já prova quem tem o domínio da situação, dado o fato de Beleza não ser muito adepto da "divisão da palavra".

Outro vídeo interessante ${ }^{11}$, ainda trecho de uma narrativa de Beleza, dá conta da crítica que ele faz à lei Maria da Penha.

BELEZA: ... uma coisa é assim, tu estimular a/hoje tem essa lei Maria ANA $^{12}$ : Maria da Penha.

BELEZA: Maria da Penha, que na minha opinião é uma coisa muito relativa, se tu não tem a estrutura, se tu não tem o apoio/quer dizer, como é que tu vai criar uma evidência/ uma mulher que tá espancada, que os filhos tão isso, tão aquilo, se ela não tem onde ficar. Tem que criar uma estrutura pra/ah, e tem outra coisa, não pode ser assistencialista, porque se não tu bota lá dentro, ela vai ficar comendo lá, bebendo, dormindo, não fazendo nada, e aí, quando voltar, vai voltar a apanhar do vagabundo de novo. (...)

\footnotetext{
${ }^{9}$ Navio negreiro é como era chamado o ônibus que levava e trazia, uma vez por dia, os moradores da Restinga para o centro de Porto Alegre nos primeiros anos de fundação do mesmo.

${ }^{10}$ Fundação de Ciência Social e Cidadania.

${ }^{11}$ Ambas os registros foram retirados da dissertação de Felipe Grune Ewald.

${ }^{12}$ Professora Dr ${ }^{\mathrm{a}}$ Ana Lucia Liberato Tettamanzy, coordenadora do projeto.
} 
BELEZA: (...) não entend/não compreendia muito isso, não conseguia entender. Então não adianta ir na delegacia, denuncia, ai fica a coitada da mulher numa pecha. Ai ela vai lá, o promotor dá o discurso dele, faz não sei o que, vai lá e fala com o advogado, vai pra imprensa... e a bobalhona fica lá, depois passa todo o fervor do negócio, o vagabundo vai lá e [gesticula]...

ALEX: senta o sarrafo...

BELEZA: senta o serrafo. Teve um inclusive até/ acho que eu dei, eu coloquei como exemplo que tinha uma mulher/digo: aqui ó fulana/ ela ia sempre lá conversar. Tu tem que decidir. Olha, não tem, tu tem que ser forte o suficiente para ter teu aparato, pra tua vida, né. Ai, no fim, a mulher diz: olha, mas o que que eu vou fazer, ele é mais forte do que eu. Não, mais forte que tu... panela tem asa pra que? [ risada geral; interrupção: filha do Beleza passa e cumprimenta a todos]. (Registro audiovisual, 06 de setembro de 2007, 39')

As perdas que se tem no momento no qual ele termina de narrar a história são óbvias: a própria história, enquanto narrativa de um fato passado na comunidade, não existe mais. O que permanece são rastros, resíduos de fatos que servem, sobretudo, ao narrador, para que ele se constitua como sujeito falante, como figura que detém algum poder.

Outra marca deixada pela narrativa de Beleza são as figuras de linguagem. Ele utiliza, frequentemente, a metáfora para explicar e/ou justificar as situações contadas. No trecho acima destacado, o próprio pesquisador, destaca a fala "panela tem asa para que?". Mais que uma figura de linguagem, Beleza quer utilizar a linguagem do seu povo para se fazer entender. Interessantes são as marcas que ele deixa em sua fala; ao contar uma narrativa para professores e estudantes de nível superior, ele busca compor um narrar rebuscado, com palavras que soem bem para a academia. Entretanto, ele não hesita em dizer que o conselho dado à mulher foi: panela tem asa para que?

Essa metáfora, por sua vez, está bastante ligada ao que ele já disse anteriormente: as pessoas precisam pensar e pensar deve ser refletir, e não algo mecânico comparável a um castigo.

Segundo Benjamin, na verdadeira narração a mão intervém decisivamente com seus gestos, aprendidos na experiência que sustentam de cem maneiras o fluxo do que é dito (1994: 221). 

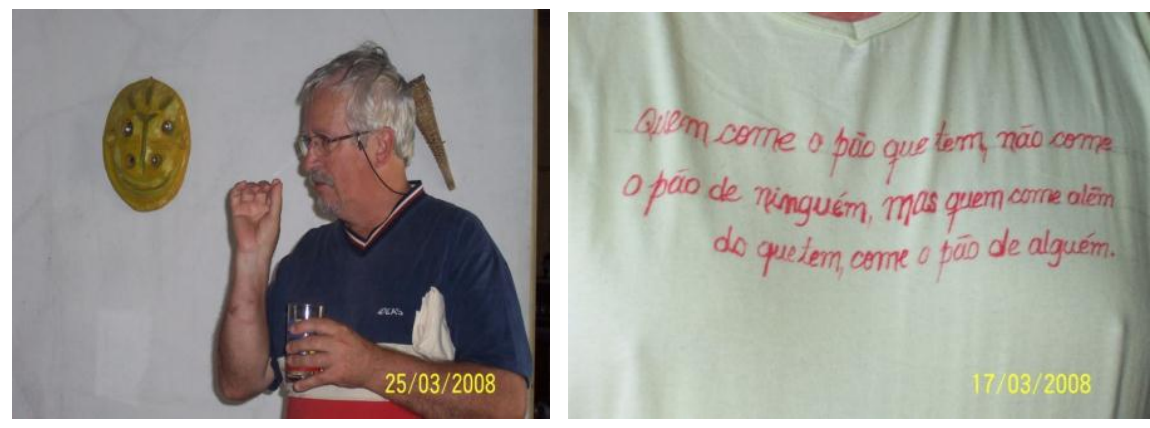

$* * *$

Essas duas imagens dão conta de características bastante importantes em Beleza: seus gestos e sua capacidade de construção poética.

Mas ainda pensando em Beleza por uma perspectiva benjamiana ele pode ser considerado enquanto um contador, na medida em que sabe dar conselhos. Aliás, muitos moradores recorrem à Beleza quando não sabem como agir e ele com sensibilidade, e a partir de metaforas criadas com base na linguagem da comunidade, dá sua colaboração em prol de uma mudança de comportamento e realidades.

Ainda sob a perspectiva de uma análise benjaminiana é interessante destacar que tanto nosso papel enquanto pesquisadores que têm o papel de transcrever fatos da oralidade para a escrita, sendo a escrita pautada no ambiente virtual, quanto a consideração de que lidamos com narradores que são parceiros e têm expectativas em relação ao nosso trabalho nos levam aos conceitos de Experiência (Erfahrung) e a Rememoração (Eingedenken), formas autênticas de memória.

A memória é o elo entre o presente e o passado por meio da tradição. Contudo, quanto mais se vive na modernidade, mais a sociedade se afasta do conceito de Experiência, visto que o avanço do capitalismo com suas formas de produção, reprodução e comercialização ocasionaram uma perda da sensibilidade e, automaticamente, da capacidade de formação das consciências coletivas que são elaboradas e revividas pela reminiscência dos agentes históricos. Perder a capacidade de narrar é perder consequentemente a capacidade de fazer com que os fatos do passado possam ser cognoscíveis. Isso é algo que, mesmo não tendo uma reflexão teórica, está bastante presente na consciência de nossos narradores. 
A memória e a lembrança, individuais ou coletivas, necessitam da vivência e da sensação de elementos existentes no tempo presente para tecer não só aquilo que foi um dia, mas também para imaginar uma cena fictícia, desejada. Muitas das cenas narradas por Beleza nos parecem ser $90 \%$ frutos de uma ficção que ele quer que seja representada como forma de se mudar o olhar para com a Restinga. A rememoração é possível pelas correspondências elaboradas pelos traços visíveis que permanecem no espaço evocando um outro tempo, atribuindo significados e dando sentido ao passado. "Pois o importante, para o autor que rememora, não é o que ele viveu, mas o tecido de sua rememoração, o trabalho de Penélope da reminiscência" (Benjamin, 1994: 37). Para Benjamin as correspondências e as memórias voluntárias e involuntárias, dialeticamente, fundiriam o coletivo e o individual. A memória voluntária seria aquela estabelecida na vivência do próprio sujeito, mas mesmo fazendo uso da inteligência, ela é incapaz de assimilar determinadas potencialidades de um tempo perdido no passado, pois ela não é regida por uma contiguidade. Já a segunda, a involuntária, traria, inconscientemente à tona, elementos vividos no passado a partir da experiência. Esses conceitos opostos foram desenvolvidos por Benjamin a partir de Marcel Proust quando este descreveu sua experiência com o sabor Madeleine (Benjamin, 1975). Já os restos fossilizados tornam-se pistas históricas com significados elaborados pelos agentes históricos daquele tempo passado a partir de uma contradição, pois são, por um lado, extinção e morte de algo que existiu, e, por outro, possibilidade para mudança, pois ali reside a transitoriedade da história. "O rastro inscreve a lembrança de uma presença que não existe mais e que corre o risco de se apagar definitivamente" (p. 44). E por isso, fazemos uso do site e dos vídeos, na medida em que os vemos como forma possível de registro e manutenção desses rastros. Nesse sentido, é importante ressaltar a tensa ligação existente entre memória e rastro, pois a memória vive a "presença do presente que se lembra do passado desaparecido, mas também presença do passado desaparecido que faz sua irrupção em um presente evanescente" (Gagnebin, ibidem). Portanto, deve-se pensar o rastro e a memória a partir da noção de ausência dupla, ou seja, nomeia-se através da palavra (que já remete a uma ausência) um objeto presente que remete a um outro objeto ou "coisa" também ausente, semelhantemente a um palimpsesto que se pode inscrever, sucessivamente, uma escrita em cima da outra. Por isso, pode-se afirmar, mesmo que paradoxalmente, a fragilidade do rastro, da memória e da própria escrita. A história prévia de um objeto revela sua possibilidade (incluído seu potencial utópico), e sua história posterior mostra no que se transformou enquanto 
objeto histórico, arrancando-o do continuum da história. As marcas deixadas pela história posterior do objeto, as condições de sua decadência e a forma de sua transmissão cultural possibilitarão que as imagens utópicas dos objetos passados possam ser lidas no presente como verdade. Para Ricoeur (1997) a experiência e o vivido ao serem narrados passam por uma transformação, ou melhor, são refigurados temporalmente. Essas narrativas pretéritas se renovam através do presente inventando o passado da cidade e construindo seu futuro, transformando, dessa forma, seus espaços e seus respectivos significados.

O fato é que quando vamos transpor as narrativas escutadas na Restinga nos deparamos com o cuidado politico que devemos ter ao lidar com elas. Sabemos do lugar que ocupamos e do lugar que nossos narradores ocupam. Em suas narrativas podemos encontrar de forma clara em uns, sutis em outras a questão da intriga da qual Ricoeur faz menção.

Ricoeur defende que as intrigas são ao mesmo tempo singulares e não singulares: narram acontecimentos que só ocorrem nessas intrigas, e que, portanto, não se encaixam automaticamente nos paradigmas disponíveis, mas tendem ao mesmo tempo a armar-se como novos paradigmas, universalizando aqueles acontecimentos que as compõem. Assim, as intrigas combinam ao mesmo tempo desvio e conformidade aos paradigmas.

Para Ricoeur, portanto, os acontecimentos, dado o fato mesmo de serem narrados, são sempre e simultaneamente únicos e típicos, contingentes e previsíveis, desviantes e tributários de paradigmas, seja de modo deliberado como no caso de uma paródia ou de uma narrativa de teor irônico ou não (leia-se aqui o caso das narrativas históricas ou jornalísticas, que, ao buscarem a objetividade no relato dos fatos, acabam por mascarar essa própria articulação). Essas narrativas que mascaram sua própria articulação tem seu lugar em nosso site e nos foram fornecidas por nossos narradores. São as reportagens, materiais escaneados, anotações de seus cadernos de que falamos anteriormente e que ajudou a compor não só nosso site, mas também nossa pesquisa como um todo; foram o elo com os moradores e o aporte teórico de entendimento do que eles compreendiam como memória de um bairro.

Postular uma cisão entre acontecimento e estrutura como sendo substâncias independentes torna-se, sob o prisma da teoria da narrativa de Ricoeur, uma tarefa pouco produtiva.

Iluminuras, Porto Alegre, v.12, n. 29, p. 199-218, jul./dez. 2011 
Encontramos em Sahlins algumas justificativas para esses eventos narrativos recolhidos na Restinga e passados para a web.

$\mathrm{O}$ pensamento de Sahlins caminha numa esteira bastante semelhante à de Ricoeur, identificando numa certa tradição dos estudos antropológicos e históricos um movimento que tende a isolar determinados eventos - marcos, alterações no painel da história e da cultura - e opô-los à estrutura - matriz que estabelece o padrão de continuidade da história e da cultura. Ora, tal oposição, julga o autor, revela-se perniciosa pelo simples motivo de que "toda estrutura ou sistema [já] é sempre eventual", isto é, só se verifica em termos empíricos por meio dos eventos, dos usos particulares que dela fazem os sujeitos sócio-histórico-culturalmente situados. Mais significativa (e talvez um pouco mais difícil de reconhecer), no entanto, é a proposição inversa, segundo a qual "todos os acontecimentos são culturalmente sistemáticos" (Sahlins, 1985/1990: 190). Com efeito, um evento é um acontecimento dotado de significância, e enquanto tal, depende da estrutura para produzir seus efeitos. Um evento não pode ser tomado simplesmente como um acontecimento isolado da experiência com o mundo, mas sim em relação à estrutura simbólica que permite que ele apareça e se torne significativo.

O que nossos narradores querem, de uma certa forma, é serem narradores de um evento que darão conta da história da Restinga e serão ferramentas na constituição de um acervo de memória, acervo esse que é físico, mas é também virtual. É como se tivéssemos, propositalmente, uma reiteração da memória do bairro, que está disponível em uma sala do Departamento de Letras da UFRGS e em várias "salas" virtuais nas quais o individuo pode acessar quando quiser e na ordem que melhor lhe convier.

Os eventos são sempre interpretados, ou como diria Ricoeur, armados-emintriga. É assim que uma separação essencialista entre estrutura e evento (acontecimento com significância) se apresenta mais como um ato de vontade, um esforço metodológico, que propriamente uma descrição objetiva da realidade.

E é dessa forma também que, segundo Carlos Lopes, Sahlins vê na dinâmica das práticas de agentes situados a própria possibilidade de transformação de categorias e valores culturalmente estabelecidos.

Se uma dicotomia entre estrutura e acontecimento é pressuposta, ela viria a ser problematizada de forma mais explicita no âmbito das teorias pós-estruturalistas, as quais se propunham ser uma reavaliação do primado da estrutura com base no pensamento lévistraussiano. 
Para o estruturalismo, a estrutura preexistiria ao acontecimento: as regras, a gramática e mesmo a ideologia sobredeterminariam os acontecimentos, os quais se constituem como marcações pontuais. A estrutura, assim, ditaria o que o acontecimento significa, ou mesmo se ele é digno ou não de significar (ter significância). A História, por exemplo, tida como uma progressão linear do tempo, configuraria uma estrutura idealizada, invariável e homogênea, uma vez que se a enxerga como reflexo transparente dos fatos da realidade. Os eventos históricos, dessa forma, seriam o próprio modo de acesso à estrutura. Eles, por assim dizer, evidenciariam, ou confirmariam, a estrutura.

De qualquer maneira, a ligação entre estrutura e acontecimento permanece sempre no trabalho da significação. O que freqüentemente ocorre é que as diferentes comunidades interpretativas buscam atribuir universalidade às suas próprias estruturas, tratando-as como se fossem a-históricas. As estruturas nunca são ahistóricas; elas se modificam constantemente (e potencialmente) a cada ato de ressignificação de um determinado evento. Em outras palavras, o evento é sempre capaz de modificar a estrutura, ainda que gere a ilusão de imutabilidade e ahistoricidade dessa mesma estrutura.

Esse evento pode ser narrado, também, em ambiente virtual e ainda assim vai estar dando conta de estórias que são históricas, que referem, sobretudo no caso da Restinga, acontecimentos vistos como fatos históricos na medida em que constituem a identidade dos sujeitos moradores do bairro. À remoção por eles sofrida são atribuídas algumas vitórias e muitas derrotas.

\section{Algumas conclusões}

A análise do site "A Vida Reinventada" traz a tona diversos fatores que perpassam quem contou, quem transcreveu, quem editou o vídeo disponível, mas sobretudo os critérios que quem traduziu utilizou. Sendo critérios que estão no âmbito do coletivo, a escrita digital permite uma análise que dá conta das escolhas feitas e do que foi deixado para trás. O que foi deixado para trás é o que se perde e essa perda advêm da individualidade do tradutor que por determinado motivo resolveu deixar um fator de fora. O caráter de parceria, nesse sentido, é mister para que menos erros no momento da transcrição sejam cometidos. O foco é publicar os fatos, por eles considerados, históricos e que possibilitam uma reafirmação da sua identidade e da sua 
história. Muitos pontos ainda deixam interrogação, interrogações estas as quais objetivo transformar em afirmações em minha tese.

\section{Referências}

BENJAMIN, Walter. Obras Escolhidas I. Magia e técnica, arte e politica: ensaios sobre literatura e história da cultura. São Paulo: Brasiliense, 1994, - Obras Escolhidas III. Charles Baudelaire: um lírico no auge do capitalismo. São Paulo: Brasiliense, 1994.

CARVALHO, Rogério. $O$ Imaginário de Gilbert Durand. Disponível em http://www.docstoc.com/docs/11616093/A-antropologia-do-imaginario-de-GilbertDurand. Trecho extraído de projeto de pós-doutorado. Acesso em: 08 outubro 2010. DURAND, Gilbert. A Imaginação Simbólica. São Paulo: Cultrix, Editora da Universidade de São Paulo, 1998.

ECKERT, Cornélia; ROCHA, Ana Luiza Carvalho. "A cidade e suas crises, o patrimônio pelo viés da memoria: por que e como preservar". In: Revista Habitus, v. 4, n.1. Goiânia: Instituto Goiano de Pré-História e Antropologia/ UCG , 2006. p. 455-470. Disponível em: http://seer.ucg.br/index.php/habitus/article/viewPDFInterstitial/364/302. Acesso em: 15 de agosto de 2010.

"A Cidade, O Tempo e a Experiência de um Museu Virtual: pesquisa antropocronotopológica nas novas Tecnologias". In: Revista Iluminuras, v.1, n.1. Porto Alegre: PPGAS/ UFRGS, 2000.

GAGNEBIN, Jeanne Marie. História e Narração em Walter Benjamin. São Paulo: Perspectiva, 2009.

GUILARDUCCI, Claudio. Memória Urbana: um espaço construído e um tempo contado. Disponível em: http://www.unirio.br/espacoteatral/iv-seminario-textoguila.html. Acesso em: 28 de setembro de 2010.

LOPES, Carlos Renato. "Lendas Urbanas: narrativas entre o acontecimento e a estrutura". In: Revista Eutomia, ano 1, n.2. Recife: UFPE, . p. 318-342.

PERRONE, Maria Paula S. de Bueno. A imaginação criadora em Jung e Bachelard. Disponível em: http://www.ip.usp.br/laboratorios/lapa/versaoportugues/2c30a.pdf. Acesso em: 8 de outubro de 2010.

POLLAK, Michael. "Memória, esquecimento, silêncio". In: Estudos Históricos, v. 2, n. 3. Rio de Janeiro: CPDOC/FGV, 1989, p. 3-15.

RICOEUR, P. Tempo e Narrativa. Tomo I. Campinas: Papirus, 1994. Tempo e Narrativa. Tomo II. Campinas: Papirus, 1995. . Tempo e Narrativa. Tomo III. Campinas: Papirus, 1997.

SAHLINS, Marshall. Ilhas de História. Rio de Janeiro: Jorge Zahar, 2003.

Recebido em: 22/12/2010

Aprovado em: 30/03/2011 